Agro-Science Journal of Tropical Agriculture, Food, Environment and Extension Volume 17 Number 1 (January 2018) pp. 7 - 19

ISSN 1119-7455

\title{
INNOVATION DEVELOPMENT AND TRANSFER BY AGRICULTURAL DEVELOPMENT AGENCIES: A CASE STUDY OF COWPEA IPM IN NORTHERN GHANA
}

\author{
Esther, W. \\ CSIR-Water Research Institute, P. O. Box 38, Accra, Ghana \\ Author's e-mail: ewahaga@yahoo.com
}

\begin{abstract}
This paper draws on data collected during 12 months of fieldwork in Northern Ghana. The fieldwork researched two communities in two districts of Northern Ghana and three Agricultural Development Agencies (ADA); Savanna Agricultural Research Institute (SARI), the Ministry of Food and Agriculture (MOFA) and World Vision Ghana (WVG). Data collection was achieved through formal surveys, Focus Group Discussions (FGDs) and observations. A total of 120 individual interviews were conducted for the formal survey guided by the questionnaire. Thirty individual questionnaire-10 each-were administered to the three ADA-SARI, WVG, and MOFA. Again documentation of activities from the three ADA was gathered. While 275 community members made up of both male and female farmers, elders and traders were involved in five FGD Workshops. This paper focuses on ADAs and innovation development, diffusion and adoption in agriculture and the impact thereof on men and women in increasing agricultural productivity. It further focuses on how agricultural policies influence the processes of innovation development, diffusion and transfer. Results indicate that targeting and getting farmers involved at an early stage in innovation development and transfer is important for any agricultural development programmes and for adoption. Indications were that imbalances in the delivery of extension services had negative impacts on making available appropriate innovations, especially to women farmers. Thus monitoring and evaluation aid the direction of agricultural policies and improve on innovation development and transfer techniques. Again, successful innovation development, transfer and high rates of adoption are the result of good collaborative work; a product of good research planning, monitoring and evaluation and information sharing.
\end{abstract}

Key words: change agent, extension, agricultural productivity, agricultural policies

\section{INTRODUCTION}

Agriculture plays a very important role in the economies of many countries with the most commonly cited justification for government intervention in agriculture being food security. Therefore, whilst the intervention in the agricultural sector in developing countries is also highly political, its implications for the growth of the domestic economy and for the reduction of poverty are far greater (Miers 2011). Policies guarantee developing countries a right to protect key sectors of their economy such as the agriculture sector (Miers 2011). Technology innovation and subsequent transfer is generally recognized as an essential for sustainable growth. Technology development comes about as a result of changing needs of consumers and farmers where indigenous technologies are not yielding the desired results. Therefore to meet the desired technological needs of farmers and consumers in the agricultural sector, technology development and transfer that involve the various interest groups is paramount. Policy is a very vital tool for directing development especially in developing countries. Agricultural policies and how they govern innovation development and transfer, is also important. Agricultural Development Agencies have played important roles in developing agricultural in the study area. Over the past years, they have worked closely with farmers in rural communities in improving cowpea production through the cowpea Farmer Field School (FFS). By working with rural farmers ADA's have drawn on farmer's expertise to help develop further cowpea IPM innovations. The development of the agricultural sector in recent years has indeed been attributed to advancement in innovation development and dissemination; this is important because agriculture is the most important economic sector.

The Development of Innovations/Technologies The work of Rogers, Biggs, Okali and Bose up contributes to the past and current understanding of the processes involved in innovation development, diffusion and adoption. Rogers (1983) argues that the development of innovations begins with the recognition of a need or problem, which then 
stimulates research and development activities that are designed to solve that problem or need. According to Rogers (1983), a change agent is an individual who influences a client's decision to innovate in a way deemed desirable by a change agency. Mostly, a change agent points out new alternatives to existing problems, which clients then adopt. However, a change agent may also attempt to slow the process of diffusion to prevent the adoption of certain innovations deemed undesirable; for example in the case of farmers adopting chemical pesticides for the prevention of both field and postharvest insects. Innovations must be developed to match a client's needs or problem. For innovations to be developed to meet client needs, feedback from the client system must flow from client to the change agent and to the change agency so that it can make appropriate adjustment/developments on the basis of previous successes and failures (Rogers 1983). Change agents must have knowledge of their client's need, attitudes, and beliefs, their social norms and leadership structure, if programmes of change are to be tailored to fit the clients (Rogers 1983).

Where change agents have knowledge of their clients' needs, attitudes and belief technological development is considered a major tool for growth especially in African agriculture. As there is a pressing need to meet the demands of poor people in areas with resource constraints (Biggs 1990; Sumberg and Okali 1997). Due to increases in population, there is demand on land so severe that soil fertility is reduced unless greater input levels are made use of. Again, an increase in population puts pressure on land thus reducing farmers' chances of practicing the traditional fallow system; this eventually renders farmland infertile. The traditional fallow system allows farmers to leave their land uncultivated for a number of years so that soil fertility can recover before it is cultivated again. Thus potential for good agricultural productivity can be maintained. Where there is a reduced soil fertility level on the farms, more artificial chemical pesticides inputs have to be used and more innovations developed to increase agricultural production. As a result, rigorous agricultural innovations with higher purchased input levels and increased labour requirements have been initiated in several regions of Sub-Saharan Africa (Lawrence, Sanders and Ramaswamy 1999).

According to Okali, Sumberg and Farrington (1994), agricultural innovations come from a number of different sources, which are best discussed using the two main models outlined by Biggs (1990): that innovation is developed and transferred through either a central or multiple sources of innovation. The ability of farmers to participate is of major interest. Concerns surrounding farmer participation in innovation typically concern farmers' understanding of new innovations, their participation in the development process, their empowerment, the role of local organizations and the comparative gain of diverse research and development institutions (Okali, Sumberg and Farrington 1994). Further to their discussions, Okali, Sumberg and Farrington (1994) made note of the fact that there is a rapidly growing literature that embodies debates around the theoretical and practical aspects of farmer involvement in research. Monitoring and evaluation strategies, tools and indicators were thought to play a vital role in assessing the impact of farmer participation and hence the development of innovations (Okali, Sumberg and Farrington 1994). For instance, looking at Ghana, in developing strategies for Cowpea Integrated Management Programmes, farmers could be consulted for their input as to how to tackle their development. In this instance, farmers' involvement is very essential as every region in Ghana is different in terms of geographic and cultural characteristics. Targeting farmers and getting them involved at an early stage is important; as they become part of the successes and failures of an innovation.

Furthermore, Biggs argues that some farmers might consider certain innovations as 'old' and others as 'new'. Some kinds of innovations are often seen as 'old or new' depending on the individual farmer using or looking at them. For instance a farmer who learns how to cultivate cowpea using the Integrated Pest Management strategies in the south of Ghana, which is the first place for the dissemination of most innovations, will view them as 'old' innovations, when the innovation is transferred in the northern part of Ghana, whereas his colleagues will view them as 'new'. This is especially true for institutional innovations concerning the way research is structured, organized and managed (Biggs 1990). For example every institution behaves differently towards any innovation and the outcome of any given innovation depends on the nature of the innovation and the institutions involved. Recent interest in developing and promoting new on-farm systems research methods has most people discovering, rediscovering, and labelling previously known approaches and innovations as 'new' (Biggs 1990). Whereas it is difficult to identify whether an innovation is really 'new', what is important is to actually recognize the actual use and potential for such an innovation (Biggs 1990). Okali, Sumberg and Farrington (1994) argue that in the 1970's there was already a move from the linear model. The linear model proposed that farmers should be provided with alternatives which they themselves have helped determine, and among which they can choose. Practices in innovation development, transfer and adoption, need to increasingly acknowledge and value the role of local wisdom and solutions. Indeed innovations that are generated 
locally are not just more likely to be culturally appropriate, but also likely to be utilised by the potential adopters. When adopters are externally persuaded to buy into the vision of an outside expert, they tend to demonstrate inertia and resistance, much like the Iowa farmers who for years resisted the adoption of hybrid seed corn (Rogers 1983; Biggs 1990; Rogers 1995). For Okali, Sumberg and Farrington (1994), to be effective, research cannot be disassociated from the increased awareness of the importance of local knowledge. Research has to incorporate/integrate farmers' local knowledge if it will to enhance farmer participation. Secondly, Okali, Sumberg and Farrington identified an important synergy through the interaction of formal agricultural research and farmer's own research. However the level of interaction between farmers and agricultural researchers varies depending on objectives and the specific innovations under study (Okali, Sumberg and Farrington 1994). According to Okali, Sumberg and Farrington (1994) described how the Pan-American Agricultural School dealt with the significant but complex to study categories of farmer knowledge, which, he argued, are especially challenging to address in a collaborative manner. Thus in the school's pest management programme, the emphasis was on two things: the ADA's learning from the farmer and the farmer learning from the ADA's on cowpea production.

\section{Diffusion of Innovations/Technologies}

In this section it is argued that the linear model is of limited value in understanding the usefulness of the multiple model. The idea of communicating the use of new innovations from one person to another in a social setting is very important for development. These new ideas refer to innovations and the process of communicating innovations to modify the behaviour of the receiver is referred to here as diffusion (Rogers 1995). The theoretical perspective of 'diffusion of innovations' is concerned with how, why, and at what rate new ideas and innovation spread through cultures. According to Rogers, the diffusion of innovations describes the process by which an innovation is communicated through channels over time among members of a social system (Rogers 1995). The theory has potential application to innovation, and has been used as the theoretical basis for a number of innovative research projects. Research in diffusion of innovations argues that disciplines ranging from agriculture to marketing have used diffusion theory to increase the diffusion of innovative products and ideas (Rogers 1995; Yates 2001). Rogers (1995), recognizes four factors that affect, contribute or influence the diffusion and adoption of an innovation. These include; the information on which the innovation is based; strategies for transfer of innovation; time; and the nature of the society within which it is introduced. When an innovation is diffused without prior investigation as to the needs and wants of the people, taking into consideration the norms and values of the people and innovations already in use, it may lead to low rates of adoption. Generally, information from the end users and the innovators (before and after the diffusion of innovation) is vital in achieving high adoption rates. With information from the end users, it is easier to disseminate new or improved innovations. Thus it is important for researchers developing an innovation to know the appropriate channels to use when disseminating a new innovation to ensure effective dissemination and understanding by the end users. This shows that where a technology is disseminated, it will either be adopted or rejected subject to constraints identified during the innovation dissemination process. Rogers identified two types through which change in behaviour through dissemination of innovation can occur. The first is imminent change, which occurs within and among members of a social system. The second, he identified as contact change which occurs when external sources to the system introduces new innovations (Rogers 1983; Rogers 1993).

Time is essential in the diffusion of innovation. Rogers (1995) argues that a vital factor in the diffusion process is the element of time, which is often ignored in behavioural research. When end users of an innovation are given much more time to understand fully the innovation being disseminated, it is more likely to yield good results. Langyintuo et al. (2000) refer to the process of innovation adoption as the innovation-diffusion model, which holds that access to information about an innovation is the key factor determining adoption decisions. They further argue that if the innovation is appropriate, the problem of innovation adoption is reduced to communicating information on the innovation to the potential end users (Langyintuo et al. 2000). This is a kind of technological solution to the problems of technological dissemination that might give people more knowledge about a new innovation. So when knowledge is disseminated to people it will not simply lead to behavioural change. This contradicts the model by Rogers that suggest that people will adopt or reject an innovation subject to the limitations identified during the innovation dissemination process. An important component of the dissemination process which has received little research attention is discontinued adoption, where an innovation is rejected after having previously been adopted (Inaizumi et al. 1997). Rejecting an innovation could arise as a result of new and more effective innovations being disseminated, the ineffectiveness of an innovation or inability on the part of users of an innovation to apply the innovation as required due to inadequate dissemination. Gedikoglu (2010) 
claims there were no theoretical models of innovation dis-adoption until his study titled, Impact of Farm Size and Uncertainty on Technology Dis-adoption. In this work he predicted that large-scale farmers were more likely to disadopt innovations if the cost of replacing an old innovation with a new one is the same. Agricultural extension has been described as a channel of innovation dissemination (Sumberg and Okali 1997). The agricultural extension service, which concerns itself with giving instructions and practical demonstrations in improved farming practices, is the main avenue for disseminating to rural farmers in Ghana improved tools, the use of fertilizers and high yielding seeds (Date-Bah 1985). The agricultural extension service according to Opare (1979-1980) has been in operation in Ghana since 1890; its personnel are mainly male (DateBah 1985). Farmers who have regular visits from agricultural extension agents are considered to be more likely to accept new and improved innovations as they are exposed to how new innovations work through demonstrations; part of the dissemination process. According to Nnanyelugo et al. (1997) and Inaizumi et al. (1997), there is a positive and significant association between age, farming experience, training received, socio-economic status, cropping intensity, aspiration, economic motivation, innovativeness, information source utilization, information source, agent credibility and adoption (Inaizumi et al. 1997). Innovation dissemination can be a formal or informal process and so individuals are involved in this process in their daily lives as they strive to a living. This literature thus brings to bear an understanding of how dissemination is undertaken by agents of innovation dissemination.

\section{METHODS AND MATERIALS}

\section{Research Location and Sources of Data}

This paper draws on data collected during 12 months of fieldwork in northern Ghana. The northern region, as one of the ten regions of Ghana, is divided into 13 districts and the research was conducted in two of them. The communities in which the research was conducted sit some $102 \mathrm{~km}$ and $15 \mathrm{~km}$ from Tamale, the Northern Regional Capital. The communities involved in the study in the two districts were; Kpasa and Tamalbila. Tamalbila is located in the Tolon Kumbungu district and had a population of around 1000 inhabitants. Kpasa, with a population of about 800 , is located in the West-Mampusi district. Predominately agriculturally based, the study area relies on farming as a major source of income and food for household consumption.

The research was conducted in an atmosphere of confidentiality: participants' rights, privacy and interests were respected. Steps were taken to maintain confidentiality of the identity of the communities and research participants. Participants were given clear information and assurances of how data will be stored and about the confidentiality of information collected from them. These were read by those who could do so, and interpreted to those who could not read and write. The names of the place are common knowledge but the informants were assured of confidentiality and especially where people could be hurt now or in the future. The fieldwork also researched three ADAs: Savanna Agricultural Research Institute (SARI), the Ministry of Food and Agriculture (MOFA) and World Vision Ghana (WVG). The following methodology aims to collect data to determine how gender concerns raised in the 1970's has altered gender roles in recent times thereby documenting the gendered nature of productive and reproductive roles in the agricultural sector.

\section{Methodology, Sampling Procedure and Data Collection}

Questionnaires for the interviews were semistructured and open ended. In the first instance, thirteen prospective communities were identified. These communities were Kasalgu, Tampie-Kukuo, Malsheigu, Kumbuyili, Gumo, Nwodua, Kpenjing, Cheyohi, Nwangbong-Yepala, Walewale, Logri, Kukua and Yendi. Out of this sample, two communities were randomly selected using an online random choice generator. The actual names of the communities involved were changed to Tamalbila and Kpasa; these are pseudonyms. Thirty individual questionnaire - 10 each - were administered to the three ADAs-SARI, WVG and MOFA. Again documentation of activities from the three ADA was gathered. Seven household were observed in the study communities; three in Tamalbila and four at Kpasa. Households that had been involved in agricultural activities with the three ADAs were numbered and randomly selected using an online random choice generator. Observations were structured to capture major points of interest such as the agricultural and nonagricultural roles played by all household members. A total of 120 individual interviews were conducted for the formal survey guided by the questionnaire while 275 community members (see Table 1), made up of male and female farmers, elders and mostly female traders were involved in five Focal Group Discussion (FGDs) Workshops. The individual interviews were mostly for household heads or their representatives but the female respondents were either household heads or asked to be interviewed in place of the household head, this was to ensure that a good number of women participated in the study. This was achieved with the help of household heads. Without their permission, it would have not been possible to interview women in place of household heads when there were male headed households. There were 
only 5 female headed households in Tamalbila and 2 in Kpasa. Three FGD workshops were held in Tamalbila and two FGD workshops in Kpasa. Cowpea was used because the three ADAs have done extensive work together on cowpea.

\section{RESULTS AND DISCUSSION \\ Results}

The results are mainly from individual interviews and institutional documentation of activities from the three ADAs.

\section{Agricultural Policies and Innovation Development, Transfer and Adoption}

To promote widespread innovation dissemination and adoption, agricultural policies today emphasize farmer-to-farmer innovation transfer, and in the case of this study area, it was gathered from the three ADAs and the communities through individual interviews that the three ADAs involved have trained men and women leaders in the study villages to complement extension delivery. This, it was gathered through individual interviews, has intensified the formation of women's groups, and improved access to extension services of their members.

An important agricultural policy guiding innovation development and dissemination is a periodic monitoring and evaluation of agricultural programmes. In monitoring and evaluation, it was gathered at MoFA through individual interviews that, new innovation or programmes are monitored in terms of being effective, acceptable, cost effective, and environmentally friendly and not conflicting with the customs and traditions of end users. Monitoring and evaluation is intended to find out how well farmers are doing with information transferred to them. This is done in the form of follow-up assessments and the information gathered is analysed and interpreted according to the objectives of the programme. Results from individual interviews from MoFA showed that in doing monitoring and evaluation of newly developed and improved innovations, some key indicators are used to measure performance and one of these is the level of involvement of women. The participation of women is therefore paramount as close to 40 percent of the farmer population is women. Monitoring and evaluation therefore aid the direction of agricultural policies and improve on innovation development and transfer techniques. It also enhances the participation of women who are significantly involved in the agricultural sector. Current, agricultural policies aim at improving institutional coordination. This includes the collaboration between ADAs to make use of their varied strengths in the development of the agricultural sector. It therefore promotes coordination and collaboration between the three ADAs to improve the cost-effectiveness of innovations developed and transferred as gathered through individual interviews. Thus modernizing the agriculture sector in which productivity and production improvements are based on science and innovation encourages the prioritization of research based on targeted crops such as cowpea. This guides the promotion of science and innovation in agricultural development and so research activities are motivated by the end users; farmers and consumers. As a result, the Government endeavour through policy implementation to improve the uptake of innovations by improving relevance of innovations to users and their access to the innovations. It was gathered through individual interviews with the three ADAs that they have improved the effectiveness of research, extension and farmer linkages to increase participation of end-users in innovation development. This has increased the capacity for social and economic research by SARI for sustainable development. The involvement of farmers in innovation development therefore encouraged scientist to develop highyielding, short-duration and pest resistant crop varieties according to individual interviews from SARI. As a result, effective post-harvest management strategies, particularly storage facilities are developed and tailored to the needs of rural farmers. This strategy was designed to foster adoption, and even improved innovation development which translated into increased agricultural production and therefore development in the agricultural sector. This strategy and its objectives is at the core of the cowpea IPM innovation development and dissemination through the cowpea FFS. The essence of technology development and transfer is emphasized in the agricultural policies of Ghana. The goal of the national plant protection policy is to achieve an efficient system to ensure crop losses caused by biological, environmental and ecological factors are contained in a sustainable and economical manner. It aims at reducing crop losses caused by pests and diseases from 30-50 percent to 10-15 percent. However, there was potential for gross misuse, abuse and misapplication of pesticides to control pre and post-harvest losses of cereals and legumes resulting from field and storage pests and diseases. In recent years the three ADAs have contributed significantly to agricultural policy formulation. This is because of their exposure in facilitating knowledge and innovation transfer to farmers, it was gathered. The three ADAs are engaged in programmes both nationally and internationally. As a result they gather information on practices in other countries through workshops and collaborative projects to aid in reshaping agricultural policies in Ghana. Again some agricultural policies are reshaped to suit the particular need of the region. 
Table 1: Participation in Interviews and FGD Workshops

\begin{tabular}{lllllll}
\hline Community & Interviews & Women & II Men & FGDs FGDsFGDs & Women & Women Men \\
\hline Tamalbila & 60 & 20 & 40 & 165 & 95 & 70 \\
Kpasa & 60 & 20 & 40 & 110 & 45 & 65 \\
WVG & 10 & & & & & \\
MOFA & 10 & & & & 140 & 135 \\
SARI & 10 & 40 & 80 & 275 & & \\
Total & 150 & & & & & \\
\hline
\end{tabular}

Collaboration among the Three Agricultural Development Agencies in Developing and Transferring Agricultural Innovations

Demand for agricultural commodities is rapidly increasing, especially for high value products like cowpea. These changes have opened up opportunities for increased productivity, greater demand for innovations and increased participation for both female and male farmers. This is the reason for which collaboration is important between the three ADAs. The purpose of this collaboration as it was gathered was to better facilitate the development and transfer of agricultural innovations to rural farmers; both men and women.

One example of this collaboration is how teams from the three ADAshad come together to work on interventions that involve the development and dissemination of improved cowpea cultivars suitable for the northern region's harsh environment. Documents from MOFA indicated that improving on cowpea cultivars is of significance in the region as most of the improved cultivars are to a great extent drought resistant, pest resistant and have shorter maturity periods than existing cultivars. To minimize post-harvest losses often associated with cowpea in the study area, the MOFA has also introduced other appropriate cowpea innovations. Indications are that these interventions can contribute to improvements in cowpea production.

This collaboration around cowpea production was undertaken by multidisciplinary research teams-scientist from SARI, extension officers from MOFA and development workers from WVI collaborate to develop, adapt and transfer agricultural innovations to farmers. Within each agency, scientists/staff from different disciplines work together to identify/develop, test, and disseminate innovations suited to local conditions. WVI's provide technical advice and the three agencies also observe each other's' activities, offering guidance on how women could better be integrated. The agencies execute the project objectives by sharing responsibilities based on the capabilities. This is an indication that collaboration encourages the identification and use of best practices for agricultural development for the benefit of the rural poor farmers. The inclusion of NGO's and farmers who may have different skills from the main Institute undertaking a project is important here.
The main aim of this collaboration is innovation development and its dissemination. For several years, these three agencies have transferred cowpea IPM innovations to farmers in various parts of the northern region, including the Upper East and Upper West regions. The agencies spent several weeks of planning during the IPM implementation phase where they intensively involved participants: three days were allocated each week for the implementation and the remarks of Dawuni, a project officer of MOFA demonstrates the advantages of the approach: 'Collaboration between MOFA, SARI and WVI is strong. The cowpea IMP project is one such example. We planned together even with the farmers and we had all participants coming up with different, intelligent and interesting ideas.' In terms of breeding new cowpea lines that are early maturing, high yielding and pest and disease resistant, SARI has sole responsibility for their development, with international funding. WVG has in some instances provided funding but not technical advice. WVG has a comparative competency in innovation transfer and maintains a healthy collaborative relationship with SARI and MOFA in the northern region. Abebe, a MOFA project manager explains this working relationship: 'In breeding cowpea and other crops we do not collaborate much. When we collaborate, we only do so to collect data on farmers' preferences but the actual breeding is done by SARI.'

The three agencies collaborate by preparing and implementing work plans and setting targets for the adaptation, development and transfer of innovations. To do this, SARI implements adaptive research activities, while WVG and MOFA undertake transfer activities, with SARI facilitating the transfer process. In implementing adaptive research, SARI assesses the adaptability of research already undertaken by the core agricultural research scientist. SARI complements collaborative relationships between MOFA and WVG in innovation dissemination as SARI does not work directly with farmers but mostly offers technical advice. This has improved working relationships between WVG, SARI, MOFA and farmers. Apart from collaborating to select appropriate innovations for testing, the three ADAs monitor the progress on the field, participate in field days, and jointly analyze and interpret the data collected. This type 
of interaction between SARI's scientists, and MOFA and WVG's project officers strengthens the collaboration and contributes to interdisciplinary interaction which provides a better understanding of the agricultural development and the processes involved. Exchange of expertise has been encouraged and facilitated by the collaborative activities between the three ADAs. Scientists from SARI have learnt about extension skills from MOFA, WVG and farmers, as farmers are directly involved in the dissemination process. Scientists from SARI have also learnt from MOFA and WVG how to work closely with farmers: as MOFA staffs are directly involved with farmers. This helps scientists from SARI in the innovation development and dissemination process. Scientists from SARI sometimes work with little or no collaboration from MOFA or WVG; they apply the techniques learnt from them on how to involve farmers in developing and disseminating innovations. Thus several innovations, apart from cowpea IPM innovations, have been developed, adapted and disseminated by the three ADAs as a result of collaboration. 'Collaboration is important because WVG has a vast experience of issues relating to rural development and innovation transfer, whereas SARI works mainly on developing innovations, but we do come together to contribute our ideas on innovation development and transfer. No single agency works on its own'. Alhassan (MoFA). There is therefore every indication that collaboration between the three ADAs is benefitting the agricultural sector considering the varied expertise from the agencies. Collaborative work is very important at every level of innovation development because in the end innovation dissemination becomes more effective and sustained. So, successful innovation development and high rates of adoption are the result of good collaborative work, which is a product of good research planning, monitoring and evaluation and information sharing.

There are challenges, however. One is that SARI, MOFA and WVG often have limited expertise in gender issues, especially on issues raised by women and development policies requiring female participation. They also often lack authority in this area at the grassroots level where the need to address gender issues is critical because they were not originally trained to deal with gender related issues. However, in discussions with three MOFA staff it was noted that training of MOFA staff on gender-related issues is usually undertaken through workshops and short courses that empower them tackle gender related issues with authority. Sometimes funding becomes a problem so a few staff benefit from the training. For example, during the cowpea IPM project, not only were field workers trained on how to implement the programme, but also on how to involve women.
During the discussions it emerged that there is a gap in the knowledge and skills on gender of the staff of the three ADAs. Gender issues can be tackled if the multi-dimensional and complex issues around rural women farmer's empowerment, and the context needed to enhance their capabilities is understood. It was agreed that ideally each agency should participate in workshops thereby creating networks to facilitate the exchange of best practices, encourage partnerships and undertake collective problem-solving through collaborative work. Workshops open up different opportunities and ideas to participants. Collaboration between the three ADAs and farmers is a key characteristic of the innovation development and transfer process. Without farmers' contributions, new and improved innovations are not going to work. It is the role of agencies to work out how to successfully involve farmers in all the innovation development processes through planning, monitoring and evaluation, and information sharing.

\section{The Role of the Agricultural Development Agencies in Developing New Innovations}

The findings from the research demonstrate the potential of innovation development and transfer to meet the needs of under resourced poor farmers is immense. This is important because farmer's perception and preferences for particular innovations will influence their ultimate adoption. The role of the three development agencies includes collecting baseline data, developing innovations that are suitable to farmers, sourcing sufficient funds, undertaking collaborative work and upgrading their knowledge and skills among others. Most cowpea innovations are developed at the regional level in order to ensure the incorporation of ethnic, cultural and geographic characteristics of the region and the varied expertise of regional agencies. These agencies, with their varied expertise, come together to develop cowpea innovations and the developed innovations are expected to include all the traits needed by farmers. In developing innovations, it is the role of the three development agencies to make sure they are aware of characteristics of the innovations already in use that are not effective. This is effectively done through baseline studies of current practices to give an understanding of what traits are new. Here MOFA plays a key role in initiating the surveys while SARI has a responsibility for data collection. As discussed earlier in this paper, the three ADAs have committees that meet frequently in order to discuss work in progress and to find answers to the challenges they face. Discussions with three of MOFA's programme officers indicated that, before innovations are developed or sent to the rural communities, baseline surveys are done to ensure that such innovations are in line with the social needs of the end users. Also, 
because new and improved innovations are developed by scientists from SARI, collecting baseline data will not be a difficult issue.

Innovation development therefore requires expertise with local knowledge on activities pertaining to existing innovations in use by farmers. Abebe from MOFA explained that, 'the role of the three ADAs involved in cowpea IPM innovation transfer is to consider the appropriateness of the innovation to a farmer and the ease of adoption, as complex and inappropriate innovations will not be adopted.' In developing cowpea innovations, trials are systematically carried out to establish the appropriate cowpea innovation. These trials are first of all carried out by SARI and MOFA with a pilot group of farmers. Here, MOFA play a key role in locating test sites. If the innovation is suitable for the farmers, MOFA leads the dissemination process. Alhassan, who is a research office at MOFA, details this process: 'We usually pilot our new innovations before they are sent to farmers. To do this, we select a group of farmers to test it on them. For instance, if an innovation is on cowpea, cowpea farmers - both male and females- are targeted. Selection of participants is then done together with the community chairman. Usually those who are proactive in development programmes are selected if they fall under the categories we are looking for. If they like the innovations we will know soon. In testing new innovations with farmers, we usually make sure that we include men, women and the youth for us to record responses from each group of people.' Another approach was described by Davis from SARI who said; 'To know whether or not farmers are interested in what we are doing, we site our trials by the roadside. If they are impressed with the innovation on their way to their farms or the city, whichever way they go, they will stop by and ask about the innovation. This usually happens when we are trying new varieties of crops on the field.' Commenting on what Alhassan reported, the priority of the three ADAs is to support women and the under-resourced poor farmers. Hence, this development programme would appear to challenge the patterns of agricultural activity that are unfavorable to women given their input into agriculture.

It is the responsibility of the three ADAs to showcase innovations annually on farmer's day ${ }^{1}$ for other groups of people who were not involved during the transfer process, to see how the innovations work and their benefits. This triggers further adoption and or improvements in already

\footnotetext{
${ }^{1}$ The farmers' day falls on every first Friday of December and was first celebrated in 1988 through the efforts of MOFA. On this day, hardworking farmers are honoured with certificates and prizes.
}

developed innovations. People who are in different parts of the country attend these events and may also voice their opinions on the innovations. This can result in better ways of improving on existing innovations in the near future and in adding to already existing knowledge on an innovation. One of the tools used to disseminate information on an innovation is to broadcast the news in both English and the various local dialects over the national and local FM radio stations, and on television. When this is done effectively local farmers, most of who have access to a radio, and possibly a TV have further opportunities to get to know what is happening in the country. When an innovation is developed and effectively broadcast, it helps to attract the attention of donors that hitherto did not have an interest in agriculture. The farmer's day help to reassure donors that the money and resources they provide are used for a good cause to achieve a desired outcome. To achieve this, the agencies involved would effectively manage the development, implementation and dissemination of innovation. Knowledge is the basis of innovation development and so therefore, as the three ADAs develop new innovations, they develop their technical skills. To do this, they have very strong ties with both local and international universities, where they arrange for their staff to upgrade their knowledge. Some have upgraded themselves from being Agricultural Extension Agents (AEA's) to being $\mathrm{PhD}$ holders holding more senior positions. Measures like this have solidified the research, development and extension base of the agricultural systems in Ghana. With this type of training and knowledge upgrade, research scientists source recent information on innovation development and transfer. Again, with opportunities like this, scientist and extension agents often attain greater heights in the field of innovation development and dissemination. This kind of training also goes to strengthen the capabilities of development agencies in developing and disseminating agricultural innovations.

\section{The Role of Agricultural Development Agencies in Innovation Transfer}

The theoretical perspective of 'diffusion of innovations' is concerned with how, why, and at what rate new ideas and innovation spread through cultures (Rogers 1995). Rogers (1995), recognizes four factors that affect, contribute or influence the diffusion and adoption of an innovation. These include; the information on which the innovation is based; communication used to spread information about the innovation; time; and the nature of the society within which it is introduced. When an innovation is diffused without prior investigation as to the needs and wants of the people, taking into consideration the norms and values of the people and innovations already in use, may lead to low 
rates of adoption. Generally, information from end users and innovators (before and after diffusion of innovation) is vital in achieving high adoption rates.

Changing the perceptions of farmers in the study area is a difficult and tricky issue to tackle because it involves modifying systems of beliefs and practices. The culture, ethics, values, beliefs and practices of the farmers involved have to be taken into consideration, as most rural dwellers in the study area believe in some of their traditions and culture. Research in northern Ghana is more concentrated on staple food crops since it is staple food crops that dominate the economy in this region. The agencies that are the focus of this paper are more concerned with the rural poor who are under resourced, but are the main producers of food crops in the region. Their role in innovation transfer is therefore very important and to be successful, involves maintaining contact with farmers over a reasonable period of time. This may extend to four years once contact has been established. During this period reports on farmer's progress on adoption are written. These reports include assessments of innovation impact, information on adoption and use of innovations transferred. However, there are only a small number of the three agricultural development agency personnel who can take up such role. If follow-up, adoption and impact studies are not carried out, farmers can resort to using innovations their own way which may result in low yields. It is therefore important for the agencies to get farmers to maintain the techniques transferred to them through follow-ups. It was gathered that follow ups are done in the form of evaluations during which a team investigates the performance and impact of a transferred innovation. Guidelines are set for investigations during the follow up after which findings are analysed and evaluated to answer key questions. These are usually carried out with and among participants of a project. Follow up visits can create a positive relationship between rural poor farmers and the ADAs. It can create a sense of belonging and trust and provide farmers with a sense of their contribution. This encourages them to get involved in future dissemination programmes. In the case of cowpea, if research develops cowpea varieties that are resistant to pest in the field, it will improve the condition of the poor farmers. When cowpea insect infestations are curbed, storage becomes less of a problem. In discussions with MOFA staff, it was argued that improved quality results in increased yields, and the ability of the crop to grow in difficult environmental or stressful conditions, such as where soils are poor or where there are prolonged droughts. This means that farmers are the focal point and much research and extension revolves around under resourced poor farmers. Participatory techniques are therefore important in innovation dissemination. Cowpea innovation diffusion programmes are participatory because this has been shown to be the best way to transfer innovations. As such, participants often make active contributions to sustaining the programme. Interviews at MOFA indicated that participatory research challenges practices separate the researcher from the researched, and promotes a partnership between researchers and the people under study. It was found that the participatory research process in cowpea FFS is empowering because it brings isolated people together around common problems and needs.

The transfer of cowpea IPM innovations to farmers in this region has played a significant role in rural agricultural development. It has provided many valuable answers to issues concerning cowpea farming, as local innovations are no longer as effective and productive. For example, cowpea was stored in single bags but since the double bag or triple bag innovation was introduced, 95 percent of farmers and traders in the study area store cowpea in this way. This innovation has curbed storage insect infestations at the early stages. It was gathered that for innovations to be adopted by farmers, innovations must bear similarities to local innovations, be cost effective, high yielding and of good quality.

The transfer of new and improved innovations to women brings with it high rates of adoption, which translates into the increased agricultural productivity. Results showed that women share ideas to help improve their situation because they are involved in the day to day activities of the household and farm. They know from their daily experiences what is lacking and know what needs to be improved. Hence, there contribution of rural women farmers in developing new technologies is valuable to the three ADAs. The paper suggests that working with rural women is not straightforward. Rural women find it much easier working with female colleagues (female field workers) than male field workers, and this problem is compounded by the fact that there are very few female agricultural extension workers or even female researchers in the study area. This continues to be a problem despite efforts being made by the government to encourage educated women to work in agricultural development programmes. However, it is worth noting that there has been an improvement in the involvement of female farmers in agricultural development programmes. In spite of this increased focus on women, women face persistent cultural and economic constraints that limit their inclusion. Many men in the rural communities in the study area act as points of resistance to women's involvement in agricultural development programmes. Without the permission of men and husbands in particular, most married women are not allowed under any circumstances to take their own decisions However, in recent years 
the situation has changed somewhat and a number of women involved in this study indicated that they have more freedom to act independently now than in the past. Also, without the authority of males in a group meeting of both men and women, the women are not usually allowed to make contributions or ask questions. These are all the prerogative of the male or household head. However, results showed that, the exclusion of women takes a different form, as they are allowed to participate in the programmes, but their contributions are still restricted and controlled by the participating males.

As a result, women often prefer to be in different groups, separated from men to enhance their participation and to increase their influence over the decision-making process. As such in agricultural development work, gender involvement and gender policies play an important role. However some of these policies are altered depending on the traditions and customs of the people. For example, agricultural development workers from community ' $A$ ' might modify a gender policy to suit particular areas, circumstances and techniques involved. For instance, policy implementers might be informed by specific local circumstances as to alter policy to make room for the participation of women. Women might be separated in an environment or culture where separation of the sexes is the norm. This sensibility allows for the effective participation of women in agricultural programmes. It was noted that on separating them into a different group, some women performed better than men. First, they are comfortable and much more confident when working in women's only groups, as determined by their cultures. Second, and given the appropriate resources, they adhered to the recommended IPM strategies that saw their cowpea yield better than that of their male counterparts: they had all the resources there was to cultivate the cowpea. This shows that new opportunities are open to women when working with their female colleagues.

Training more extension volunteers could thus enhance the participation of rural women. The extension volunteer training is targeted at both male and females who did not have the opportunity to continue their education to a higher level. Discussions with Alhassan from MOFA indicated that all volunteers undergo a week's training on farm management and value chain education to enhance the transfer and sustainability of innovations. Also, they are trained in crop production and post-harvest innovations among other things. This encourages female involvement and participation, which can lead to greater improvement in women's role in agricultural production. MOFA's own data indicated that numerically, the number of women participating or
Benefiting from agricultural development programmes has increased. Also, it is not just about working with women in general but focusing attention on women who are the most marginalized. However, it is worth noting that most women in the study area are marginalized in many aspects of their lives; in the household, on the fields and in their communities. It is therefore easier for women to talk to agricultural development agency staff who are women as they may feel free to fully participate. Notwithstanding this, efforts are also being made to include women at management level meetings where decisions are made on how to work with women. This, in the longer run, will significantly enhance gender participation at the grass roots level, encourage further the introduction of gender-sensitive policies and gender help with mainstreaming in practice and policy.

The involvement of women at the management level of the development agencies provides the best alternatives to achieving the three ADAs' goals of successfully involving women in their programmes. These women serve as role models, dispelling stereotypes about the capacity of women in being engaged in technologically enhanced farming, and serve also as mouth piece for the women. Such women have experienced what it is to be marginalized in their communities, homes and work place, and have some ideas of how to go about ensuring that the status of women in similar situations is improved. However, there are only a handful of such women in the region, because literacy rates among girls are very low and the opportunities to acquire the necessary educational qualifications are very limited. SARI, MOFA and WVG do consider issues of gender as to be paramount in innovation transfer. This is important because rural farmers do not always understand the benefits of both men and women working together at achieving the same goals. They struggle to come to terms that women should be allowed to participate fully in innovation transfer programmes. So, it is the role of the three ADAs to educate and raise awareness of rural folk (both men and women) of the need to include women. Without such education and/or enlightenment, it is often difficult to carry out agricultural development programmes. For good reason then, women are required to be part of all diffusion programmes carried out by the three ADAs. To ensure high female participation, the three ADAs make it a point to consider women by involving a minimum percentage of females in their programmes. It is important to consider that women are not allowed to sit with men at meetings. This should therefore be handled tactically to achieve the desired results without problems arising. If there are problems as a result, further agricultural development programmes are often not successful. 


\section{DISCUSSION}

Agricultural Policies and the Processes of Innovation Development and Transfer Cowpea farming has been confronted with low yields due to field and storage pests. However, in recent years efforts have been made by the three ADAs involved in this study to develop improved field and storage innovations that bring about vast improvements in cowpea yields. It is the policies of the agencies in regards to this that this section will consider in greater detail.

The three ADAs collaborate to enhance innovation development and transfer of cowpea cropping innovations. The three agencies, SARI, MOFA and WVI work with other funding agencies to develop and transfer agricultural innovations to farmers. This collaboration was found to support the more effective sharing of knowledge and skills in developing and transferring innovations to farmers and also the sharing of responsibilities for turning technological development into practical achievements. In terms of the collaboration between the agencies, Okali and Sumberg (1997) suggest that what makes development agencies more effective when they work together, or closely, is that collaboration by itself strengthens their human resource capacities. In the same manner, the sharing of expertise between three ADAs working at the study sites enhances their human capacity. Thus, by working together MOFA, WVG and SARI have been able to improve their action to mainstream gender in their programmes, and improved on their ability to work directly with rural farmers. This would have been difficult to achieve had they worked independently. The importance of gender issues in innovation development and transfer has been taken seriously by each of the three ADAs. From the findings it was established that gender targeting for innovation dissemination is part of their agricultural policies, and these policies are followed closely. Their aim is to ensure that women famers constitute about 40 percent of participants involved in all their agricultural development programmes. Importantly, this commitment to gender mainstreaming is underpinned by systems for monitoring and evaluation. The Ghana Vision 2020 is worth noting in this context as it has played a major role in mapping out policies for the agricultural sector, and then for ensuring that these policies are attentive to the needs of female farmers. All three ADAs claimed that they adhere to these policies yet the findings established implementation lapses. Examples of this included the inability of MOFA to involve its gender unit at all times and even in all activities that relate to women farmers. This agency commitment is nevertheless important. As Inaizumi et al. (1997) indicate monitoring and evaluation of improved innovations can reduce this-adoption rates, and can lead to improvements in innovations developed and ways of disseminating new or improved innovations. Findings from this study also indicate that once an innovation has been transferred to farmers, the three agencies maintain contact with the farmers, in order to monitor the adoption process, and to tackle issues such as disadoption that might occur. An example of this is the case of cowpea IPM innovations that were transferred to farmers in the study area and where it was confirmed that, as of 2008, there was agricultural extension staff still involved in evaluating farmer use of the new innovations. Biggs (1990), Okali, Sumberg and Farringron (1994) and Rogers (1983) all argue that feedback from farmers to ADAs makes agricultural research and innovation diffusion more effective. Processes of monitoring and follow up work would thus seem crucial to both maintaining but also improving effective processes of innovation development and transfer.

This study also established that a lack of female agricultural workers employed by the agencies was a problem. This is because in order to work with women farmers in productive and sensitive ways, it is often necessary to use female agency workers. I have attributed this lack of female agency workers to the low level of literacy in the study areas, and thus to the difficulties the agencies face in recruiting suitably qualified workers. Importantly, MOFA is training female school leaver as agricultural extension volunteers with the aim of placing them with women farmers. Despite MOFA's efforts however, there are only a small number of female school leavers available for such training and so problems in recruiting even adequate numbers of female volunteers may occur. It was noted that if the volunteers are well trained, and continue to receive more support from the agencies, then it is possible that such an initiative will have long term benefits. Progress however, in this direction continues to be slow. The female extension volunteers in the near future will need to serve as the link between the three ADAs and female farmers in the study areas.

Another important issue is the need for appropriate incentives to continue to motivate the staff of the three ADAs. The study revealed that incentives were an effective way of maintaining momentum, especially where recognition is given at the national or regional level for good practice. Where awards are given to individual development workers they feel their work is appreciated and has concrete results. Encouragement in itself is very important for the development of one's abilities and capabilities as it also encourages the sharing of knowledge and skill between the agricultural development workers themselves, and with farmers. The research literature indicates that it is important to highlight the role of agricultural extension services in agricultural development 
(Whitehead 1991). Similarly, it was found that publicly rewarding farmers who practised improved innovations also encourages innovation adoption in the wider community and is an effective way of increasing the willingness of farmers to participate in innovation diffusion programmes. Farmers who receive awards are often thought to be the best in the communities and are often consulted by their colleagues and the agricultural development workers who work in the communities. The availability of funds for agricultural research plays a crucial role in innovation development, transfer and adoption. It was found that if funds are readily available for research to develop suitable innovations, there is a likelihood of a high rate of adoption in this area of Ghana. However, funding from the Government of Ghana for agricultural research remains at relatively low levels and arguably is not sufficient to the task. Importantly, the research indicated that most of the innovations developed and transferred to farmers in the study areas are externally funded by international development agencies rather than the national government.

\section{CONCLUSIONS}

The agricultural policies have indeed shaped the agricultural sector of the study area. Most importantly, the ADAs have played an important role in the involvement of women in agricultural development programmes. This has increased the awareness of many women of the need to participate in agricultural development programmes and has also empowered women in decision making, both at home and on the farm. Through agricultural policy gender sensitization tactics has been stepped-up thus encouraging rural male farmers to allow female participation in the agricultural sector programmes. Collaboration has been the backbone of the agricultural sector in the study region. Through the collaborative work of the three ADAs, innovations have been developed and disseminated to farmers. This has been made possible through the varied expertise that can be found among staff of the three ADAs. By using participatory techniques, farmers also play an important role in the development and dissemination of innovations. For instance, where innovations are adapted or developed by the three ADAs, for instance through baseline surveys, pilot studies, trials and demonstrations, innovations that suit farmer's needs are developed. Again, the dissemination process of the cowpea IPM innovations requires a great deal of farmer's participation. So farmer's participation is important in the collaborative work of the three ADAs. In innovation development and dissemination, the three ADAs have specific roles to play. It has been found that SARI plays the lead role in the development of innovations with a greater input from MOFA, whereas MOFA and WVI play important roles in the dissemination process. In fulfilling their roles in innovation development and dissemination, the combined expertise of the three development agencies is critical. Baseline studies prior to innovation development are thought of as key to innovation development, as it spells out the needs of farmers and the characteristics that are required in new agricultural innovations. Innovation transfer is therefore an important aspect of the activities of the three ADAs. In the development and transfer of innovations, the Institutes make them participatory in order to encourage the adoption and use of such innovations. In making their programmes participatory, they end up lifting the confidence of the rural poor farmers thereby creating a sense of responsibility in them in terms of innovation development and transfer.

Women's issues are very critical issues however, and there is an indication that the three ADAs, particularly MOFA and WVI, have to some extent developed the expertise of their staff to confidently tackle gender issues at the rural level. Their ability to delve into gender issues is an indication that they are to some extent aware of the importance of gender sensitization issues, which is a critical agricultural policy issue in the agricultural sector. When policies are well implemented and collaborations well-undertaken, agricultural innovations will be well disseminated. In this case, women will not be excluded thus their contribution in the agricultural sector can be even more significant; an achievement that the agricultural sector aim at.

\section{REFERENCES}

Biggs S. (1990). A multiple source of innovation model of agricultural research and technology promotion. World Development, 18 (11), 1481-1499.

Date-Bah E. (1985). Technologies for rural women of Ghana: Role of Socio-Cultural Factors. In Ahmed, I. (ed) Technology and Rural Women: Conceptual and Empirical Issues. London: George Allen and Unw in, 7 211-251

Gedikoglu H. (2010) Impact of farm size and Uncertainty on Technology Disadoption. Selected Paper Prepared for Presentation at the Southern Agricultural Economics Association Annual Meeting. Orlando, FL http://ageconsearch.umn.edu/bitstream/56431/2/Imp act $\% 20$ of $\% 20$ Farm\%20Size\%20and\%20Uncertaint y\%20on\%20Technology\%20Disadoption\%20Main \%20Text.pdf. Accessed 20/07/2012

Inaizumi H. Singh B.B. Sanginga P.C. Manyong, V. M., Adesina A.A. and Tarawali S. (1997). Adoption and impact of dry-season dual-purpose cowpea in the Semiarid Zone of Nigeria, Nigeria: IITA 
Langyintuo A.S. Gyasi K.O., Abatania L.N. and Terbobri P. (2000).. Farmers strategy for sustainable food security: determinants of the Adoption of Improved Rice Varieties in the Inland Valleys of Northern Ghana: A Tobit Model Application. Bamako: SADAOC Foundation

Lawrence P.G., Sanders J.H. and Ramaswamy S. (1999). The impact of agricultural and household technologies on women: a conceptual and quantitative analysis in Burkina Faso. Agricultural Economics, 20, 203-214

Miers H. (2011). 'Talking Gender to Africa'. African Research Institute, London

Nnanyelugo D.O., Ngoddy P.O., Okeke E.C. and Ngwu E.K. (1997). Impact of a Cowpea Research project in Nigeria Using the Rapid Rural Appraisal Technique Singh, B.B., Mohan Raj D.R., Dashiell, K.E., and L.E.N. Jakai (eds) Advances in Cowpea Research. Co-publication of Institute of Tropical Agriculture (IITA) and Japan International Centre for Agricultural Sciences (JIRCAS), Ibadan, Nigeria. 29, 333 - 340
Okali C., 2010. Searching for New Pathways towards Achieving Gender Equity Beyond Boserup.ESA Working Paper No. 11-09. Oxfam, 2009.Investing in Poor Farmers Pay: Rethinking how to invest in Agriculture. Oxfam Briefing Paper

Okali C., Sumberg J. and Farrington J. (1994).farmer participatory research: rhetoric and reality. London: Intermediate Technology Publications for Overseas Development Institute

Rogers E.M. (1995). Diffusion of innovations. $4^{\text {th }}$ ed. New York: Free Press

Rogers E.M. (1983). Diffusion of innovations. $3^{\text {rd }}$ ed. London: Collier Macmillan

Sumberg J.E. and Okali C. (1997).Farmer's experiments: creating local knowledge. boulder: lynne rienner

Whitehead A. (1991). Food production and the food crisis in Africa. In Wallace T. and C. March. (eds) Changing Perceptions: Writings on Gender and Development. Oxford: Oxford Print Unit. 1:68-78.

Yates B.L. (2001). Applying diffusion theory: adoption of media Literacy programs in schools http://www.westga.edu/ byates/applying.htm. Assessed 20/01/2009 